\title{
Effect of propofol and memantine on erythrocyte deformability in diabetic rat model
}

\author{
Serife Mehlika Kuskonmaz ${ }^{1}$, Erdal Cicek $^{2}$, Faruk Metin Comu ${ }^{3}$, Mustafa Arslan ${ }^{2 *}$, Omer \\ Kurtipek $^{2}$
}

\begin{abstract}
Objectives: In this study we aimed to investigate the effect of diabetes on erythrocyte deformability (ED) and whether it can be changed by an NMDA antagonist propofol or an NMDA agonist, memantine, Several clinical studies showed that ED decreases in diabetes. Recent studies showed that erythrocytes have N-methylD-aspartate (NMDA) receptors (NMDA Rec) on their membrane.

Methods: Thirty rats were allocated to five groups containing 6 rats each. Memantine was given for 30 days to diabetic rats in one group (group DM) single dose propofol injection is added to this regimen in another group (group DPM) another group received propofol only (group DP). The remaining groups were controls (group C) and diabetic controls (group D). ED was measured in each group and compared

Results: The deformability index was significantly increased in the diabetic rats $(p<0.0001)$. However, it was similar in Group DC and DP ( $p=0.551)$, Group DC and DM $(p=1.000)$, Group DC and DPM $(p=0.176)$.

Conclusions: Neither NMDA antagonist propofol nor NMDA agonist memantine affected the altered red cell rheology in diabetic rat model.
\end{abstract}

Key words: Memantine, propofol, erythrocyte deformability, diabetes mellitus, rat

\section{Introduction}

Erythrocyte deformability (ED) facilitates blood flow through the circulation in vessels of variable diameter and enables effective exchange of gas and metabolic products in capillaries (1). ED is a function of; 1) red cell geometry, 2) viscosity of intracellular fluid, 3) erythrocyte membrane (2).

Several clinical studies showed that ED decreases in diabetes (3-5). Diabetes affects erythrocyte metabolism and function through different ways. Metabolic changes in erythrocytes lead to oxidative stress which is shown to affect erythrocyte shape in in vitro studies (6). Diabetes also affects composition of the lipid bilayer in cell membrane by increasing cholesterol and more importantly phospholipids thereby decreasing the cholesterol to phospholipid ratio $(7,8)$. Glycosylation of the cytoskeletal proteins is supposed to affect the viscoelastic properties of the membrane $(9,10)$.

Recent studies showed that erythrocytes have N-methyl-D-aspartate (NMDA) receptors (NMDA $\mathrm{Rec}$ ) on their membrane. Activation of NMDA Rec resulted in volume changes, changes in cytoskeleton and nitric oxide synthesis (11).

In this study we aimed to investigate the effect of diabetes on ED and whether it can be changed by an NMDA antagonist propofol or an NMDA agonist, memantine.

\section{Materials and Methods}

\section{Animals and Experimental Protocol}

This study was conducted in the Animal Laboratory of Gazi University upon the approval of the Experimental Animals Ethics Committee of Gazi University. All of the procedures were performed according to the accepted standards of the Guide for the Care and Use of Laboratory Animals.

In this study, 30 male Wistar Albino rats weighing between 250 and $300 \mathrm{~g}$ were used. The rats were kept under 20-21 ${ }^{\circ} \mathrm{C}$ at cycles of 12-hour daylight and 12hour darkness and had free access to food and water until 2 hours before the anesthesia procedure. The animals were randomly separated into five groups, each containing 6 rats. Groups were as follows:

Diabetes was induced by a single intraperitoneal injection of streptozotocin (Sigma Chemical, St. Louis, MO, USA) at a dose of $55 \mathrm{mg} \cdot \mathrm{kg}^{-1}$ body weight. The blood glucose levels were measured 72 hours following this injection (GlucoDr Super Sensor, Allmedicus, Korea). Rats were classified as diabetic if their fasting blood glucose (FBG) levels exceeded 250 
mg.dl ${ }^{-1}$, and only animals with FBGs of $>250 \mathrm{mg}^{-\mathrm{dl}^{-1}}$ were included in the diabetic groups (diabetes only, diabetes plus propofol and diabetes plus memantine after propofol). The rats were kept alive 4 weeks after streptozotocin injection to allow development of chronic diabetes before they were exposed to propofol.

Thirty rats were allocated to 5 groups. The groups were as follows:

Group C (Control),

Group D (Diabetic),

Group DP (Diabetic+Propofol),

Group DM (Diabetic+Memantine),

Group DPM (Diabetic+ Memantine+Propofol).

In group DP $(\mathrm{n}=6) 150 \mathrm{mg} \cdot \mathrm{kg}^{-1}$ of propofol (Propofol 1\% Fresenius $20 \mathrm{~mL}$ ) was injected intraperitoneally. In group DM (n=6) $20 \mathrm{mg} \cdot \mathrm{kg}^{-1}$ of memantine was given (Memantine hydrochloride, Sigma mg. $\left.\mathrm{ml}^{-1}\right)$ for 30 days. In group DPM $(\mathrm{n}=6)$ rats were given $20 \mathrm{mg} \cdot \mathrm{kg}^{-1}$ of memantine (Memantine hydrochloride, Sigma mg. $\mathrm{ml}^{-1}$ ) for 30 days and at the last day of experiment $150 \mathrm{mg} \cdot \mathrm{kg}^{-1}$ of propofol was administered, while rats in group $\mathrm{C}$-control $(\mathrm{n}=6)$ and group D-diabetic control $(n=6)$ received intraperitoneal physiological saline.

All rats were anesthetized with intraperitoneal ketamine $100 \mathrm{mg} \cdot \mathrm{kg}^{-1}$ at the end of the experiment. Rats in DP and DP + memantine groups were given ketamine specifically 30 minutes after propofol administration and euthanized to collect blood samples. The abdomen was shaved and each animal was fixed in a supine position on the operating table. The abdomen was cleaned with $1 \%$ polyvinyl iodine and when dry, the operating field was covered with a sterile drape and median laparotomy was performed. Blood samples are collected from the vessels in the abdominal cavity. Heparinized whole blood samples were used to prepare erythrocyte packs. Deformability measurements were done by erythrocyte suspensions with $5 \%$ hematocrit in phosphate buffered saline buffer.

\section{Deformability measurements}

Blood samples were taken carefully and analyzed immediately to avoid hemolysis. Collected blood was centrifuged at $1000 \mathrm{rpm}$ for ten minutes. After removal of serum and

buffy coat on erythrocytes, isotonic PBS buffer was added to collapse erythrocytes and this mixture was centrifuged at $1000 \mathrm{rpm}$ for ten minutes. Liquid on the upper surface was discarded. The mixture is washed three times to obtain pure red cell packs. A suspension of 5\% hematocrit was prepared by mixing the red cells with PBS buffer. The suspension was used for the measurement of deformability. Collection and deformability measurements of erythrocytes were done at $22{ }^{\circ} \mathrm{C}$.
The constant-current filtrometer system was used for measurement of erythrocyte deformability. Samples were prepared as $10 \mathrm{ml}$ of erythrocyte suspension and PBS buffer. The flow rate was held constant at $1.5 \mathrm{ml} / \mathrm{min}$ with an infusion pump. The 28 $\mathrm{mm}$ nucleoporin polycabonate filter with a $5 \mu \mathrm{m}$ pore diameter was used. The pressure changes during passage of erythrocytes through the filter were detected by the pressure transducer and the data was transferred to computer with the help of MP 30 data equation systems (Biopac Systems Inc, Commat, USA). Pressure changes are measured various times to calculate the necessary values via computer programs. A pressure calibration of the system was performed each time before measuring the samples. First the buffer (PT) and then the erythrocytes (PE) were passed through from the filtration system and the changes in pressure were measured. The relative refractory period (Rrel) was calculated by relating the pressure value of erythrocyte suspension to pressure value of buffer. Increase in Rrel was interpreted as a decrease in erythrocyte deformability $(12,13)$.

\section{Statistical analysis}

Statistical Package for the Social Sciences (SPSS, Chicago, IL, USA) 17.0 program was used for statistical analysis. Variations in blood glucose level, erythrocyte deformability were assessed by using Kruskal-Wallis test. Bonferroni adjusted MannWhitney U test was used after significant KruskalWallis to determine which group differs from the other. Results were expressed as mean \pm standard deviation (Mean $\pm \mathrm{SD}$ ). Statistical significance was set at a $p$ value $<0.05$

\section{Results}

Blood glucose measurements were $81.7 \pm$ $5.5,345.1 \pm 48.3,355.7 \pm 78.6,328.5 \pm 81.5,352.8 \pm$ $77.6 \mathrm{mg} / \mathrm{dL}$ for Group C, DC, DP, DM and DPM, respectively. Serum glucose was detected to be significantly lower in Group $\mathrm{C}$, when compared to Groups DC, DP, DM and DPM $(p<0.0001$, respectively).

The deformability index was significantly increased in the diabetic rats $(p<0.0001)$. However, it was similar in Group DC and DP $(p=0.551)$, Group DC and DM $(p=1.000)$, Group DC and DPM $(p=0.176)$, (Fig 1).

\section{Discussion}

Alteration of ED in diabetes is shown in several studies (14-16). In our study we also demonstrated a significant decrease in ED in diabetic rats. Increased phospholipid concentration in the membrane, glycosylation of cytoskeletal proteins and changes in ionic balance are implied as well as lipid peroxidation and endoplasmic reticulum stress (2). 


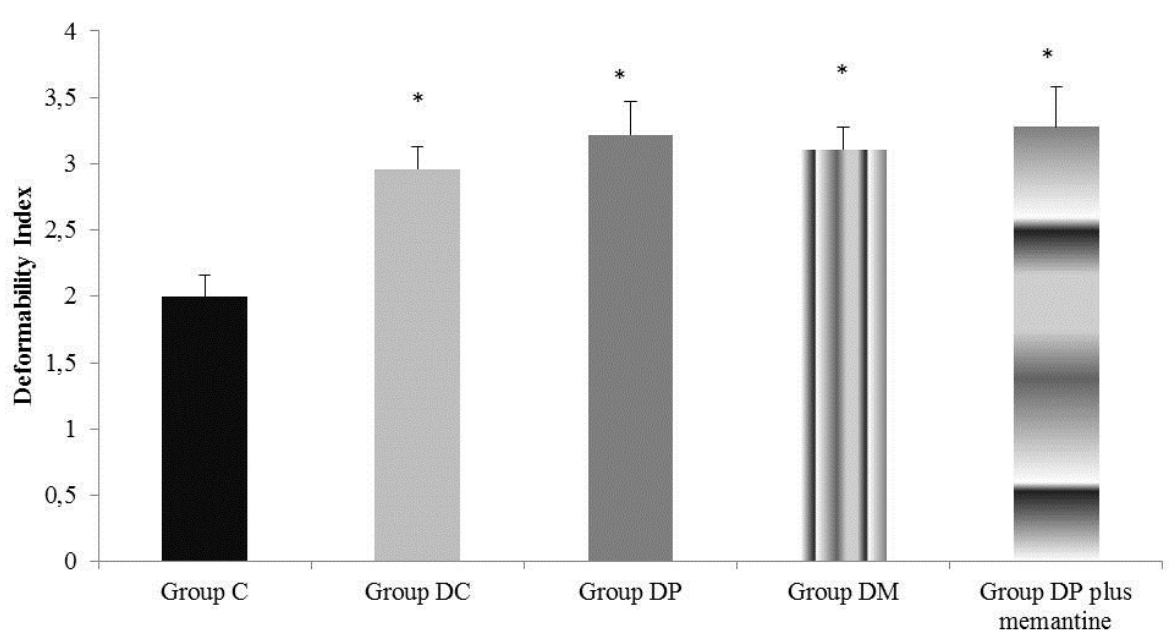

Figure 1: Erythrocyte deformability values of the groups. Each bar represents the mean $\pm \mathrm{sd} .{ }^{*} \mathrm{p}<0.05$ compared to the Group C

Among them oxidative stress may be important since an antioxidant molecule; carnosine is shown to reverse the effect of diabetes on ED and improve red cell rheology (17).

The presence of functional NMDA Rec on erythroid precursors and mature erythrocytes is shown by Makhro and colleagues (11). In their study, they demonstrated a calcium influx in a subgroup of cells in response to NMDA, which in turn triggered changes in cell volume and nitric oxide (NO) synthesis. A similar study in humans yielded compatible results. Increase in intracellular calcium is shown to promote cleavage of cytoskeletal proteins and plasma membrane calcium pump thus changing the rheological properties of the cell (18).

Memantine is clinically used in Alzheimer's disease and is a promising agent in neurodegenerative diseases characterized by NMDARec overactivation. Memantine inhibits NMDA Rec by binding the channel only when it is open and is trapped in the channel to prevent any further binding of agonists (19).

Reinhart and colleagues used a Myrenne aggrometer to investigate the role of NMDA in red cell rheology. The investigators failed to show a change in biophysical properties of human erythrocytes via activation or inhibition of NMDA receptors by homocysteic acid and memantine respectively (20).

Our results are consistent with the findings in this study. Although memantine binds to NMDA receptors and at least a subgroup of red cells are shown to have these receptors, memantine does not seem to affect red cell rheology.

Propofol is a sedative hypnotic agent which activates $\gamma$-aminobutyric acid (GABA) receptors directly and inhibits the NMDA receptor and reduces calcium influx through slow calcium channels (21).
In our study, we observed that propofol does not affect ED in diabetic rat model. There are contradictory results regarding the effect of propofol on red cell rheology in literature. Propofol is shown to increase relative resistance of erythrocytes in rats (13) On the other hand, a study on diabetic rat model showed no effect of propofol on ED (22) Reinhart et al incubated blood from healthy volunteers with propofol at different concentrations and reported a dose-dependent echinocytic change in erythrocytes (23). A study on patients undergoing cardiac surgery detected an increase in postoperative blood viscosity with propofol when compared to fentanyl (24). However Kim et al failed to demonstrate a significant change in ED in blood containing propofol at different concentrations (25).

\section{Conclusion}

Erythrocyte deformability was damaged in rats having diabetes. This injury might lead to further problems in microcirculation. Application of propofol and memantine did not alter red cell deformability in diabetic rats. This lack of effect may partly be due to binding properties of these agents or specific properties of red cells which do or don't bear NMDA receptors

This result may also be explained by the complex effect of diabetes on ED through variable mechanisms including oxidative stress, change in membrane lipids or cytoskeletal proteins which probably may not be changed simply by activation or inhibition of NMDA receptors

\section{Acknowledgement}

All authors state that there is no conflict of interest 


\section{References}

1. Chien S. Red cell deformability and its relevance to blood flow. Annu Rev Physiol. 1987;49:177-92

2. Shin S, Ku Y, Babu N, Singh M. Erythrocyte deformability and its variation in diabetes mellitus. Indian J Exp Biol. 2007;45(1):121-8

3. Brown CD, Ghali HS, Zhao Z, Thomas LL, Friedman EA Association of reduced red blood cell deformability and diabetic nephropathy. Kidney Int. 2005;67(1):295-300.

4. Banerjee R, Nageshwari K, Puniyani RR. The diagnostic relevance of red cell rigidity. Clin Hemorheol Microcirc. $1998 ; 19(1): 21-4$

5. Koscielny J, Latza R, Wolf S, Kiesewetter H, Jung F. Early rheological and microcirculatory changes in children with type I diabetes mellitus. Clin Hemorheol Microcirc. 1998;19(2):139-50.

6. Hayden MR, Tyagi SC, Kerklo MM, Nicolls MR. Type 2 diabetes mellitus as a conformational disease. JOP. 2005;6(4):287-302.

7. Mawatari S, Saito K, Murakami K, Fujino T. Absence of correlation between glycated hemoglobin and lipid composition of erythrocyte membrane in type 2 diabetic patients. Metabolism. 2004;53(1):123-7.

8. Maksina AG, Daĭniak BA, Sebko TV, Kniazev IuA [Effect of insulin on lipid peroxidation in the erythrocyte membranes of patients with insulin dependent diabetes mellitus]. Biofizika. 1997;42(3):671-4.

9. Picart C, Dalhaimer P, Discher DE. Actin protofilament orientation in deformation of the erythrocyte membrane skeleton. Biophys J. 2000;79(6):2987-3000.

10. Schwartz RS, Madsen JW, Rybicki AC, Nagel RL Oxidation of spectrin and deformability defects in diabetic erythrocytes. Diabetes. 1991;40(6):701-8.

11. Makhro A, Wang J, Vogel J, Boldyrev AA, Gassmann M, Kaestner $\mathrm{L}$ et al. Functional NMDA receptors in rat erythrocytes. Am J Physiol Cell Physiol. 2010;298: 131525 .

12. Tatlican S, Duran FS, Eren C et al. Reduced erythrocyte deformability in active and untreated Behçet's disease patients. Int J Dermatol. 2010; 49 (2): 167-71.

13. Arslan M, Comu FM, Ișik B et al. Effects of a general anaesthetic agent, propofol, on erythrocyte deformability. Bratisl Med J. 2010; 111 (3): 126-8.

14. Babu N, Singh M. Influence of hyperglycemia on aggregation, deformability and shape parameters of erythrocytes. Clin Hemorheol Microcirc. 2004;31(4):27380 .
15. Resmi H, Akhunlar H, Temiz Artmann A, Guner G. In vitro effects of high glucose concentrations on membrane protein oxidation, G-actin and deformability of human erythrocytes. Cell Biochem Funct. 2005;23(3):163-8.

16. Diamantopoulos EJ, Kittas C, Charitos D, Grigoriadou M, Ifanti G, Raptis SA. Impaired erythrocyte deformability precedes vascular changes in experimental diabetes mellitus. Horm Metab Res. 2004;36(3):142-7.

17. Yapislar H, Aydogan S. Effect of carnosine on erythrocyte deformability in diabetic rats. Arch Physiol Biochem. 2012;118(5):265-72.

18. Bogdanova A, Makhro A, Wang J, Lipp P, Kaestner L. Calcium in red blood cells-a perilous balance. Int J Mol Sci 2013;14: 9848-72.

19. Johson JW, Kotermanski SE. Mechanism of action of memantine. Curr Opin Pharmacol. 2006;6:61-7.

20. Reinhart WH, Geissmann-Ott C, Bogdanova A. Activation of N-methyl D-aspartate (NMDA) receptors has no influence on rheological properties of erythrocytes. Clin Hemorheol Microcirc. 2011;49(1-4):307-13.

21. Kotani Y, Shimazawa M, Yoshimura S, Iwama T, Hara H. The experimental and clinical pharmacology of propofol, an anesthetic agent with neuroprotective properties. CNS Neurosci Ther. 2008;14(2):95-106.

22. Comu FM, Ozturk L, Alkan M, Pampal K, Arslan M, Isik $\mathrm{B}$ et al. Investigation of the effects of propofol and vitamin $\mathrm{C}$ administration on erythrocyte deformability in rats with streptozotocin-induced diabetes Bratisl Lek Listy. 2014;115(7):400-4.

23. Reinhart WH, Felix Ch. Influence of propofol on erythrocyte morphology, blood viscosity and platelet function. Clin Hemorheol Microcirc. 2003;29(1):33-40.

24. Mokken FC, Henny CP, Gelb AW, Biervliet JD, Hardeman $\mathrm{MR}$, Kedaria $\mathrm{M}$ et al. The effects of propofol compared to high-dose fentanyl anesthesia on rheologic parameters in coronary artery surgery. J Cardiothorac Vasc Anesth. $1993 ; 7(1): 10-6$

25. Kim YH, Chung HG, Myung SA, Rha JH, Yang S, Nam $\mathrm{MH}$ et al. In vitro effect of clinical propofol concentrations on red blood cell aggregation and deformability. Clin Hemorheol Microcirc. 2012;51(4):287-92

Copyright (C) 2014 The Author(s); This is an open-access article distributed under the terms of the Creative Commons Attribution License (http://creativecommons.org/licenses/by/4.0), which permits unrestricted use, distribution, and reproduction in any medium, provided the original work is properly cited. 